\title{
Pediatric skull bone defect due to epidermoid cyst
}

\author{
Robert Sinurat* and Fajar Lamhot Gultom**
}

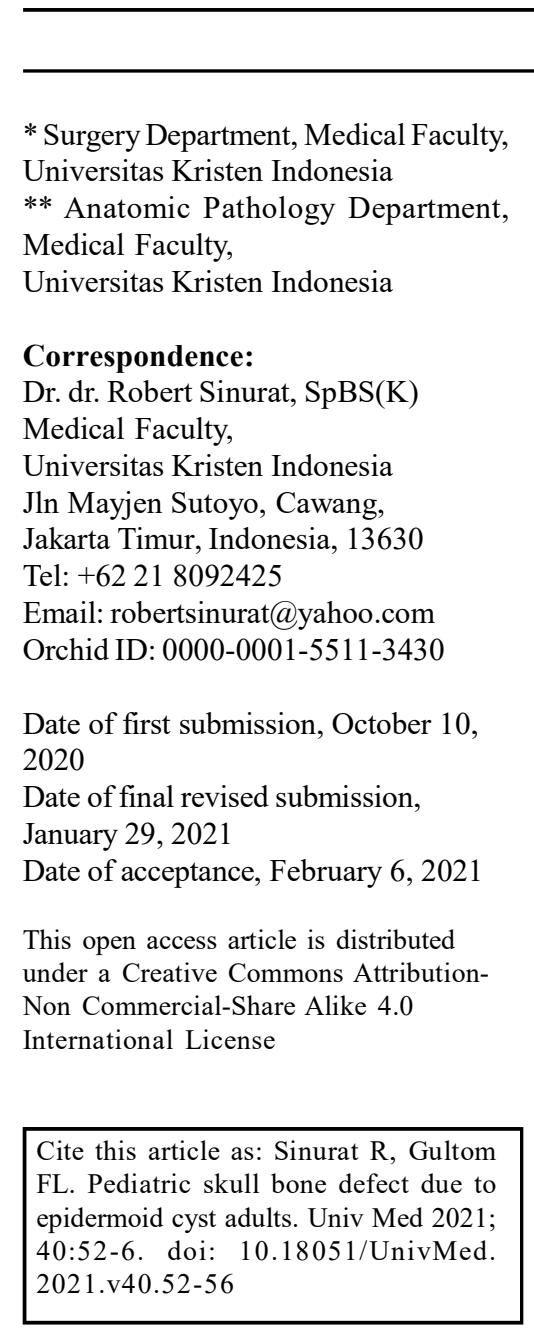

\section{ABSTRACT}

\section{BACKGROUND}

Tumors of the skull usually affect adult patients and less than twenty percent of pediatric patients. As the tumors grow, the surrounding bone may undergo destruction and erosion. When the tumors are located in the fontanel, the timely closure of the fontanel may be inhibited. Epidermoid cysts are benign tumors that are intracranially located and very rarely in the midline of the cranium. Meanwhile about $32 \%$ of stratified-squamous epithelial epidermoid cysts affect the head and neck region and only $6.7 \%$ occur in the scalp. We report an unusual epidermoid cyst located and growing in the anterior fontanel of a pediatric patient and inhibiting fontanel closure.

\section{CASE DESCRIPTION}

A 21-month-old boy and his parents visited our polyclinic because there was a lump on his anterior fontanel since four months before they came to the hospital. The lump was initially the size of a peanut and had grown to become as large as a quail's egg. The physical examination was normal and the brain CT-scan showed bone destruction without any intracranial lesion. The tumor was excised on the preoperative diagnosis of dermoid cyst. Histopathology examination showed the characteristics of an epidermoid cyst. The cyst had a wall and was full of keratin flakes without hair follicles or sebaceous glands. Follow-up one year after complete excision did not reveal any recurrence.

\section{CONCLUSION}

Epidermoid cysts in the skull of pediatric patients must be completely excised as soon as possible because their growth can damage the bone and inhibit the closure of the sutures.

Keywords: Bone defect, fontanel, epidermoid cyst, malignancy, boy 


\section{INTRODUCTION}

The majority of patients with skull bone tumors are adults and only about $19 \%$ are pediatric. ${ }^{(1)}$ Most of the lesions are malignant, with the epidermoid cyst being one of the benign pathologic lesions. Seventy five percent of epidermoid cysts are located intracranially, and the remaining 25 percent are within the diploic space of the skull. ${ }^{(2,3)}$ Nigam et al. ${ }^{(4)}$ found in their study that $32 \%$ of all cutaneous and subcutaneous epidermoid cysts were located in the region of the head and neck, while $6.7 \%$ were in the scalp. Around $23.3 \%$ of the patients was in the age range of 21-30 years, while $20.4 \%$ was in the age range of 41-50 years. Patients aged under 10 years comprised less than $7 \%$, while there were no patients under two years of age.

Epidermoid cysts in pediatric patients below two years of age and located in the midline of the skull are very rare. When the epidermoid cyst grows, the bone will be destroyed, thus inhibiting fontanel closure. ${ }^{(5)}$ These cysts are often insidious and go unnoticed for years, if ever discovered. The commonest presenting complaint is the lump without neurological deficits. Erythema, swelling and pain may occur because of inflammation. ${ }^{(2)}$ The pathophysiology of these lesions is classically attributed to incomplete neural tissue cleavage as congenital defects of neural tube closure, leading to ectodermal cell inclusion. ${ }^{(3,6)}$ Early diagnosis and proper treatment will avoid the destruction of the bone. In addition to destruction of the bone or soft tissue surrounding the tumor, many authors also have reported that the epidermoid cyst can be transformed into a malignancy with an incidence rate of $1 \%{ }^{(2)}$ Before surgery, if the lump occurs in the scalp and does not mobilize when palpated or if there is a sign of pulsation, a brain computed tomography (CT) scan or magnetic resonance imaging (MRI) examination must be performed to rule out intracranial lesions. On CT scan, the epidermoid cyst shows fluid density (hypodense), while there is low signal intensity on MRI T1-weighted images but high intensity on T2-weighted images. ${ }^{(7)}$

To date, there are no reports of an epidermoid cyst in a very young patient's fontanel and inhibiting closure of the crown because of erosion of the inner and outer tables of the skull. Here, we present a pediatric case of an unusual epidermoid cyst which is located in the fontanel, with invasion of the surrounding bone by the growing tumor.

\section{CASE REPORT}

A 21-month-old boy " $K$ " visited our outpatient clinic with his parents because there was a growing mass on his fontanel. His parents had noticed that the lump was the size of a peanut since four months earlier before they came to the hospital. The lump was becoming larger than before, and was now as large as a quail's egg. The vital signs were normal and no neurologic deficits were found. In the anterior fontanel region, there was a mass under the intact skin that was $2 \times 3 \mathrm{~cm}$ in size, soft, elastic, and not mobile when palpated.

Blood examination results were within normal limits with no signs of infection. The brain CT-scan without contrast showed a bone defect (low density) in the midline (fontanel) region. There was no intracranial lesion (Figure 1).

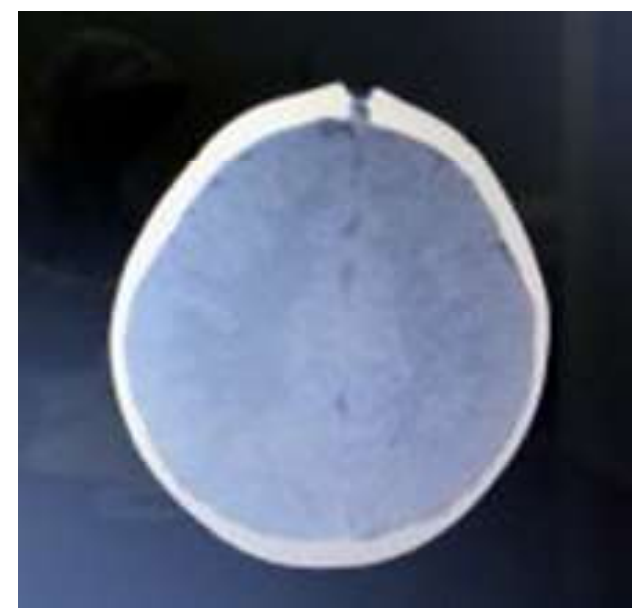

Figure 1. Brain CT-scan shows bone defect in the midline 


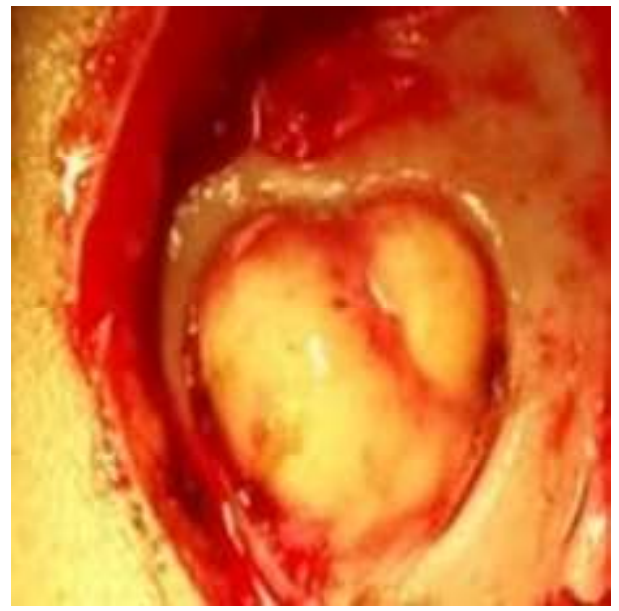

Figure 2. Tumor lies inside the bone defect, looks yellowish and encapsulated

Based on the physical examination, tumor location, laboratory and brain CT-scan results, excision of the tumor was performed on preoperative diagnosis of dermoid cyst. During surgery, after incision and dissection of the skin and fascia, the tumor was exposed, looking yellowish within the capsule inside the bone defect (Figure 2). The dura mater was intact and the tumor was removed completely with unbroken capsule.

Histopathology examination showed that the cyst wall was formed by stratified-squamous epithelial cells. The cyst was full of keratin flakes without hair follicles and sebaceous glands (Figure 3), which matches the diagnosis of epidermoid cyst. Two days after surgery, the patient was discharged and observed for one year, when there was no recurrence of the tumor.

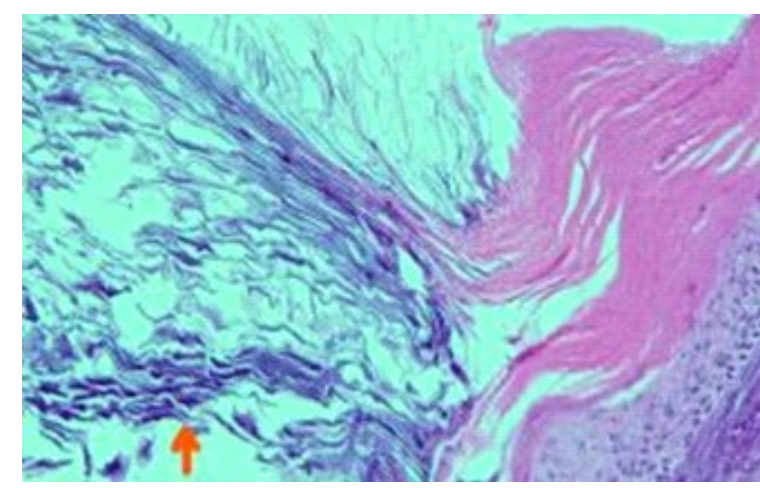

Figure 3. Histopathology result shows keratin flakes (arrow) without hair follicle or sebaceous gland

\section{DISCUSSION}

The authors report on a young patient with an epidermoid cyst on his fontanel that inhibited timely closure of the crown because of erosion of the inner and outer tables of his calvarium.

The diagnosis of this case before surgery was a dermoid cyst because it was located in the midline of the head. ${ }^{(8)}$ However, the results of histopathology examination after surgery showed the characteristics of an epidermoid cyst. Epidermoid cysts are generally located at the cerebellopontine angle and parasellar region, with less than $5 \%$ being intradiploic and intraparenchymal. ${ }^{(9)}$ Both epidermoid and dermoid cysts are lined with stratified squamous epithelial cells. Epidermoid cysts contain keratin, cholesterol and cellular debris, whereas dermoid cysts in addition contain skin appendages, such as hairs or glands..$^{(10,11)}$

Epidermoid cysts generally occur in the third and fourth decades of life. This patient was under two years old and the cyst was not present at birth. Bharti et al. ${ }^{(12)}$ have reported three cystic cases in pediatric fontanel patients. Two of them were dermoid cysts and one an epidermoid cyst, but all of the children presented the cysts from the time of birth. Their patient with epidermoid cyst was 6 months old. A study on intradiploic epidermoid cysts by Arko et al. ${ }^{(13)}$ reviewed published case reports and series that can be obtained from an Internet search engine. There were 169 cases with a mean age of 38.1 years.

The pathophysiology of epidermoid cysts especially in children is still being debated. One widely accepted theory states that it is caused by inclusion of ectodermal remnants during the process of neural tube closure. Another theory proposed for acquired-origin cases is that these cysts probably originate from implantation of epidermoid fragments into connective tissue by previous trauma. Severe spinal or head trauma is believed to be the cause of acquired intracranial epidermoid cysts. ${ }^{(3,6)}$ Lumbar epidermoid cysts can also occur because of skin 
implantation during lumbar puncture procedures.$^{(6)}$ In the present case the epidermoid cyst did not appear at birth, therefore the acquired cyst theory is the most appropriate even though the patient's parents do not remember any history of head trauma.

Epidermoid tumors on the brain CT scan show fluid density, while dermoid cysts show fat density. ${ }^{(11,14)}$ On magnetic resonance imaging, epidermoid cysts are circumscribed lesions and well demarcated. The cyst wall has low signal intensities on T1- or T2-weighted images. The MRI signal of an epidermoid cyst depends on the contents, being intermediate to slightly increased on T2-weighted images, while T1weighted images show high signal intensity. When compared to muscle, the epidermoid cyst has higher signal intensities on T1-weighted images, which is characteristic of the cyst. ${ }^{(15)}$ In the present case, the brain CT scan showed low density with bone defect without any intracranial lesions. The bone erosion is believed to be due to long-term pressure as the cyst slowly enlarges and damages the surrounding tissues, including the bone. ${ }^{(7)}$ Therefore, complete excision surgery is the treatment of choice. ${ }^{(5,11)}$ Complete excision of epidermoid cysts should also be performed effective and usually prevents cysts from recurring. ${ }^{(16)}$ However, if the epidermoid cysts has an active infection the procedure must be delayed until the resolution of infection. ${ }^{(2)}$

In most cases, epidermoid cysts managed by complete surgical resection have been cured, but $1 \%$ of stratified squamous epithelial epidermoid cysts become squamous cell or basal cell carcinomas ${ }^{(2)}$ Among all intracranial epidermoid cysts cases, around $5.8 \%$ of patients have experienced recurrences due to incomplete resection, with an estimated $44 \%$ of the recurrences having been transformed into squamous-cell carcinoma. ${ }^{(13)}$ Several authors have also found intracranial epidermoid cysts that initially had been partially resected and subsequently transformed into this malignancy. ${ }^{(17,18)}$ The signs and symptoms of rapid progression of an epidermoid cyst must be considered as marking the transformation into malignancy. The mechanism of epidermoid cyst transformation into a malignant tumor is still unclear, but some authors suspect that chronic inflammation due to cyst rupture and also partial resection of the cyst are the risk factors. ${ }^{(19)}$ The incidence of epidermoid cysts in a very young patient's scalp and skull is indeed low, but every parent should be vigilant when finding a lump on their children's head especially if it has a tendency to enlarge.

\section{CONCLUSION}

Epidermoid cysts in the skull of pediatric patients must be completely excised as soon as possible because their growth can damage the bone and inhibit closure of the sutures. Regardless of differing courses of treatment, one thing is quite clear: the exact pathogenesis and behavior of epidermoid cysts in the central nervous system remains largely a mystery.

\section{ACKNOWLEDGMENT}

I thank the patient and his parents for their approval and agreement to sign the consent forms.

\section{FUNDING}

This research did not receive grants from any agency in the public or commercial sectors.

\section{CONFLICT OF INTEREST}

None declared

\section{CONTRIBUTORS}

DS contributed to preparing and writing the original draft. RS and FLG did the review and editing. Both authors have read and approved the final manuscript. 


\section{REFERENCES}

1. Liu H, Zhang X, Zhang M, et al. Skull bone tumor: a review of clinicopathological and neuroimaging characteristics of 426 cases at a single center. Cancer Commun 2019;39:8. doi:10.1186/s40880019-0353-0.

2. Hoang VT, Trinh CT, Nguyen $\mathrm{CH}$, Chansomphow V, Chansomphow V, Tran TTT. Overview of epidermoid cyst. Eur J Radiol Open 2019;6:291301. doi: 10.1016/j.ejro.2019.08.003.

3. Enchev Y, Kamenov B, William A, Karakostov V. Posttraumatic giant extradural intradiploic epidermoid cysts of posterior cranial fossa: case report and review of the literature. J Korean Neurosurg Soc 2011;49:53-7. doi: 10.3340/ jkns.2011.49.1.53.

4. Nigam JS, Bharti JN, Nair V, et al. Epidermal cysts: a clinicopathological analysis with emphasis on unusual findings. Int J Trichol 2017;9:108-12. DOI: 10.4103/ijt.ijt 1617.

5. Oommen A, Govindan J, Peroor DS, Azeez CR, Rashmi R, Jalal MJA. Giant occipital intradiploic epidermoid cyst. Asian J Neurosurg 2018;13:51417. doi:10.4103/1793-5482.181146.

6. Kalfas F, Ramanathan D, Mai J, Schwartz S, Sekhar LN. Petrous bone epidermoid cyst caused by penetrating injury to the external ear: case report and review of literature. Asian J Neurosurg 2012;7: 93-7. doi: 10.4103/1793-5482.98656.

7. Lim J, Cho K. Epidermoid cyst with unusual magnetic resonance characteristics and spinal extension. World J Surg Oncol 2015; 13:240. DOI 10.1186/s12957-015-0651-1.

8. Lakhsmi V, Thirumurthy KS, Rabia S, Chaitra V. Intradiploic epidermoid cyst-a pearl within the skull. J Diagn Pathol 2015;9:38-42. doi.org: 10.4038/jdp.v9i2.7660.

9. Law EKC, Lee RKL, NgAWH, Siu DYW, Ng HK. Atypical intracranial epidermoid epidermoid cysts: rare anomalies with unique radiological features. Case Rep Radiol 2015;2015:528632. doi.org:10.1155/528632.
10. Reissis D, Pfaff MJ, Patel A, Steinbacher DM. Craniofacial dermoid cysts: histological analysis and inter-site comparison. Yale J Biol Med 2014;87:349-57. PMID:25191150.

11. Gaivas S, Rotariu D, Dumitrescu G, Iliescu B. Intradiploic cyst of the skul : case report. Romanian Neurosurg 2011;XVIII:1-5.

12. Bharti P, Gupta U, Bharti SK. Rare case of anterior fontanelle epidermoid/dermoid. J Pediatr Neurosci 2015;10:247-9. doi:10.4103/1817-1745.165679.

13. Arko L, Berry CT, Desai AS, Weaver M. Intradiploic epidermoid tumors of the cranium: case report with review of the literature. J Neurol Surg A Cent Eur Neurosurg 2017;78:167-79. doi: 10.1055/s-0036-1585544.

14. Choudhary G, Udayasankar U, Saade C, Winegar B, Maroun G, Chokr J. A systematic approach in the diagnosis of paediatric skulls lesions: what radiologists need to know. Pol J Radiol 2019;84;e92-111. doi: 10.5114/pjr.2019.83101.

15. Sakamoto A, Okamoto T, Matsuda S. Characteristic MRI findings of epidermal cysts categorized by size. Open Orthop J 2018;12:4628. DOI: $10.2174 / 1874325001812010462$.

16. Di Giustino F, Pecci R, Giannoni B, Vannucchi P. Cerebellopontine angle epidermoid cyst: case report. Int J Otorhinolaryngol Head Neck Surg 2013;2:5-7. doi: 10.4236/ijohns/2013.21002.

17. Agarwal S, Rishi A, Suri V, et al. Primary intracranial squamous cell carcinoma arising in an epidermoid cyst-a case report and review of the literature. Clin Neurol Neurosurg 2007; 109:888-91. doi.org: 10.1016/j.clineuro.2007.07.026.

18. Mascarenhas A, Parsons A, Smith C, Molloy C, Jukes A. Malignant squamous cell carcinoma arising in a previously resected cerebellopontine angle epidermoid. Surg Neurol Int 2017;8:186. doi: 10.4103/1817-1745.165679.

19. Ding S, Jin Y, Jiang J. Malignant transformation of an epidermoid cyst in the temporal and parapontine region: report of a case and differential diagnosis. Oncol Lett 2016;11:3097100. doi: 10.3892/ol.2016.4368. 